\title{
Short communication: Heritability of susceptibility to infection by Mycobacterium avium ssp. paratuberculosis in Holstein cattle
}

\author{
Brian W. Kirkpatrick* $†$ and Beth M. Lett* \\ *Department of Animal Sciences, and \\ †Department of Dairy Science, University of Wisconsin, Madison 53706
}

cidence for positive tests, in contrast to estimates from the threshold model, likely accounting for the difference in magnitude of heritability estimates between models and suggesting that the threshold model analysis is the better choice. Heritability estimates increased as data were restricted to herds with presumed higher MAP exposure for both linear model and threshold model analyses. These estimates are similar to previous estimates in other dairy cattle populations and suggest the potential for selection to lessen susceptibility to MAP infection.

Key words: cattle, heritability, Johne's disease, paratuberculosis

\section{Short Communication}

Johne's disease in cattle is the result of infection of the intestinal epithelium by Mycobacterium avium ssp. paratuberculosis (MAP), which leads to inflammation of the intestinal wall, loss of ability to absorb nutrients, wasting of the animal, and eventual death. A majority $(68.1 \%)$ of US dairy herds show evidence of the presence of MAP based on the most recent national evaluation effort (NAHMS, 2008). After accounting for assay sensitivity, herd prevalence from this analysis was estimated at 91\% (Lombard et al., 2013). The economic impact of paratuberculosis on the US dairy industry has been estimated to be from $\$ 200$ million to $\$ 1.5$ billion annually (Ott et al., 1999; Harris and Barletta, 2001). Of additional concern is the potential for zoonosis; whereas a link between Johne's disease in cattle and inflammatory bowel diseases in humans (Crohn's disease, ulcerative colitis) is debated, MAP has been cultured from humans suffering from Crohn's disease in multiple cases, suggesting the possibility of zoonotic transfer (Naser et al., 2014).

Johne's disease control programs typically incorporate a test and cull strategy to identify and remove from the herd cows that are infected with MAP. The 2 commonly employed tests are (1) fecal tests, in which the MAP organism is either cultured from a fecal sample or its DNA is identified by PCR amplification
Received May 4, 2018.

Accepted August 3, 2018.

${ }^{1}$ Corresponding author: bwkirkpa@wisc.edu 
of MAP-specific products from DNA extracted from a fecal sample, and (2) ELISA tests for presence of antibodies produced in response to MAP infection. Both testing approaches have high specificity, but variable sensitivity depending on stage of progression of the infection and disease (Shin et al., 2008; Norton et al., 2010). Testing by ELISA is less costly and can be applied to either blood or milk samples. The ability to perform the ELISA test on milk samples, which are routinely collected, has led to the availability of large numbers of test records in the dairy data-recording system. The objective of the current study was to use this data to estimate heritability for susceptibility to MAP infection and to test the hypothesis that a genetic variation exists for this trait.

Johne's testing records for the years 2009 to 2016 were obtained from AgSource Cooperative Services (Verona, WI) and Dairy Records Management System (Raleigh, NC). A total of 745,691 Johne's test records (ELISA) from 448,549 cows were included in the data set before editing. Data were edited to include only Holstein-sired cows from herds with at least 100 test records. Additionally, data were excluded if the Holstein sire had unknown identification or sired fewer than 50 cows in the data set. Data were further edited to include only (1) herds with at least 1 positive test, (2) herds with at least $2.5 \%$ positive test results, or (3) herds with at least $5 \%$ positive test results to examine the effect on heritability estimates of limiting data to herds with presumed higher exposure to MAP (Table 1). Johne's testing results were coded as 0 if all test records for an animal were negative and 1 if any test results were positive. A preliminary logistic regression analysis to identify significant fixed effects was performed using the glm function in $\mathrm{R}$ ( $\mathrm{R}$ Development Core Team, 2010).

Variance components for heritability calculations were estimated using ASreml 4.1 (VSNi, Hemel Hempstead, UK). Two models were used in alternative analyses, the first being a linear sire model (LM) and the second a binary threshold-probit sire model (TPM). The general form of the model in matrix notation was

$$
\mathbf{y}=\mathbf{X b}+\mathbf{Z s}+\mathbf{e}
$$

where $\mathbf{y}$ is a vector of Johne's test results (negative or positive) for daughters of sires for the LM and a vector of unobserved liabilities for being test-positive for the TPM, $\mathbf{X}$ is an incidence matrix relating phenotypes to fixed effects of herd, age at test and age at test squared, $\mathbf{b}$ is a vector of fixed effects, $\mathbf{Z}$ is a matrix relating phenotypes to sire genetic effects, $\mathbf{s}$ is a vector of sire additive genetic effects, and $\mathbf{e}$ is a vector of random residuals. For animals with multiple test records, age at test was defined as age at the last negative test if all tests were negative, or age at first positive test if 1 or more positive tests were present. The sire and residual effects were random, whereas herd and age at test were fixed effects. It was assumed for the LM that the random effects followed normal distributions of $s \sim N\left(0, \mathbf{A} \sigma_{S}^{2}\right)$ and $e \sim N\left(0, \mathbf{A} \sigma_{e}^{2}\right)$, where $\sigma_{S}^{2}$ and $\sigma_{e}^{2}$ represent additive genetic and residual variances, respectively, and A represents the numerator relationship matrix for sires. For TPM, random effects were assumed to have followed normal distributions of $s \sim N\left(0, \mathbf{A} \sigma_{S_{T}}^{2}\right)$ and $e \sim N(0, \mathbf{I} \times 1)$, where $\sigma_{S_{T}}^{2}$ and 1 represent additive genetic and residual variances, respectively, from the TPM and $\mathbf{I}$ is the identity matrix. Sire models were chosen due to consistent availability of sire identification as part of the cow Johne's test records; for over 30,000 cows with test records, dam of cow was not unambiguously identified.

Heritability was estimated using variance components for sire and residual effects as:

$$
h^{2}=\frac{\sigma_{S}^{2} \times 4}{\sigma_{S}^{2}+\sigma_{e}^{2}} .
$$

For the TPM, the underlying scale for the residual variance was 1 (Gilmour et al., 2015) for the probit link. Corresponding additive sire and residual variance components for the TPM were $\sigma_{S_{T}}^{2}$ and 1 , respectively. Both LM and TPM models were executed as restricted maximum likelihood models (Gilmour et al., 2015).

The average and median proportion of positive test results for herds was 5.6 and $4.2 \%$, respectively (Figure 1 ), when considering all herds (including those with no

\begin{tabular}{|c|c|c|c|c|c|}
\hline Data included & $\begin{array}{l}\text { Number of } \\
\text { test records }\end{array}$ & $\begin{array}{l}\text { Number } \\
\text { of herds }\end{array}$ & $\begin{array}{l}\text { Number } \\
\text { of sires }\end{array}$ & $\begin{array}{c}\text { Linear model } \\
\text { estimate }\left(\mathrm{h}^{2} \pm \mathrm{SE}\right)\end{array}$ & $\begin{array}{l}\text { Threshold model } \\
\text { estimate }\left(\mathrm{h}^{2} \pm \mathrm{SE}\right)\end{array}$ \\
\hline Herds with at least one positive test & 222,872 & 719 & 999 & $0.041 \pm 0.004$ & $0.157 \pm 0.014$ \\
\hline Herds with $\geq 2.5 \%$ positive tests & 162,413 & 555 & 815 & $0.050 \pm 0.004$ & $0.174 \pm 0.016$ \\
\hline Herds with $\geq 5 \%$ positive tests & 65,289 & 310 & 475 & $0.062 \pm 0.007$ & $0.186 \pm 0.021$ \\
\hline
\end{tabular}

Table 1. Estimates of heritability for susceptibility to infection by Mycobacterium avium ssp. paratuberculosis using linear and threshold models 
positive test results). These values are not necessarily reflective of within-herd incidence of Johne's disease or MAP infection in US herds, as it is unknown to what extent these records reflect whole-herd testing. Higher herd proportions ( $69.1 \%$ for the highest herd included) may reflect selective animal testing, which would overstate incidence relative to actual incidence. In a preliminary logistic regression analysis herd $(P<0.005)$,
A Distribution of Tests per Animal

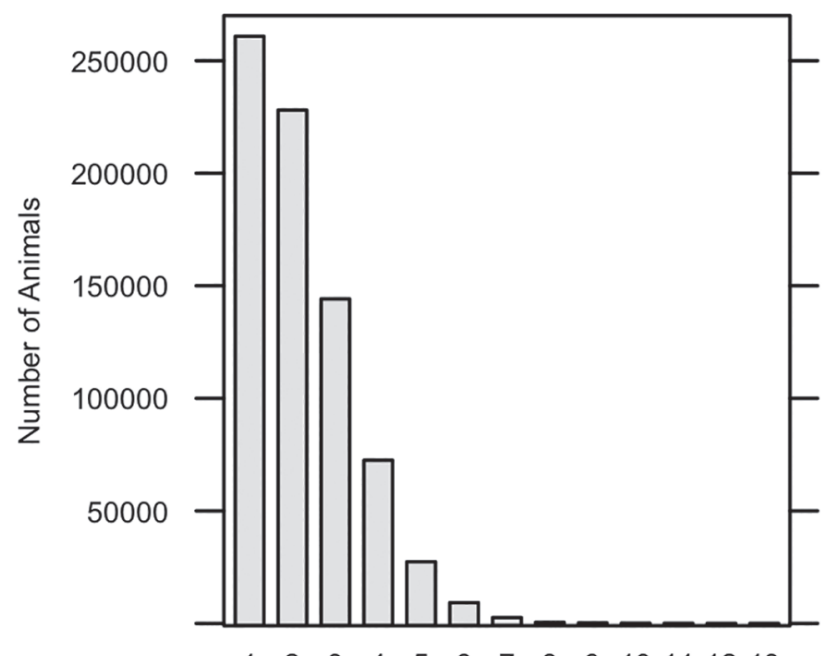

Number of Tests per Animal

C

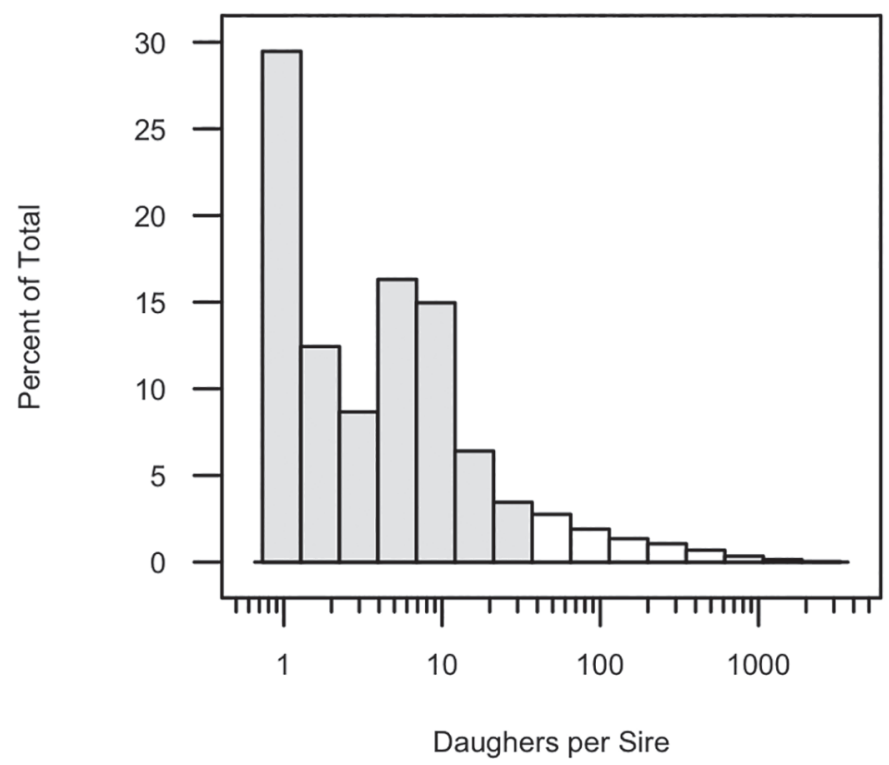

B

Records per Herd

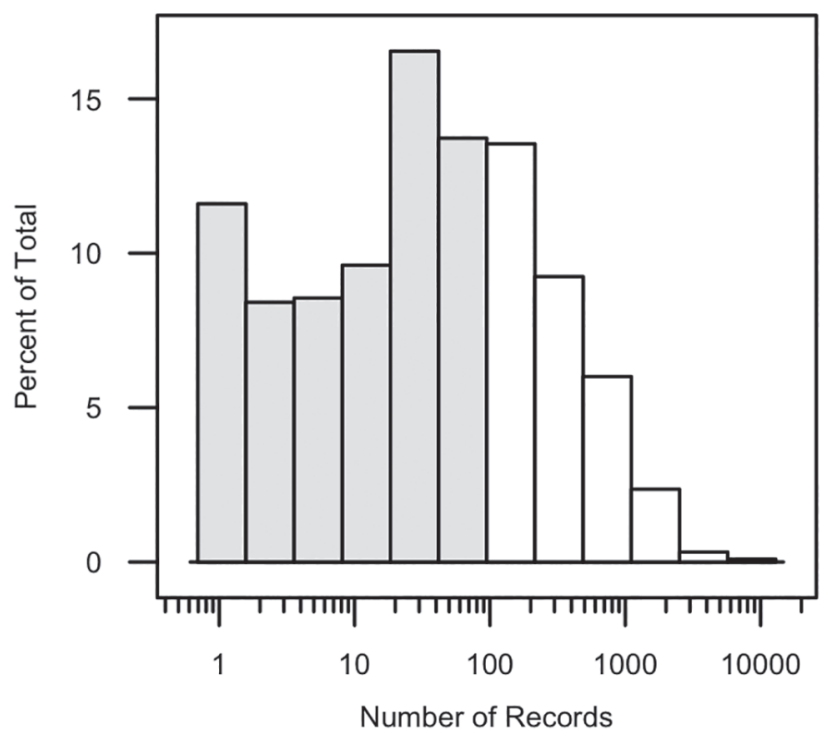

D Proportion of Positive Tests by Herd

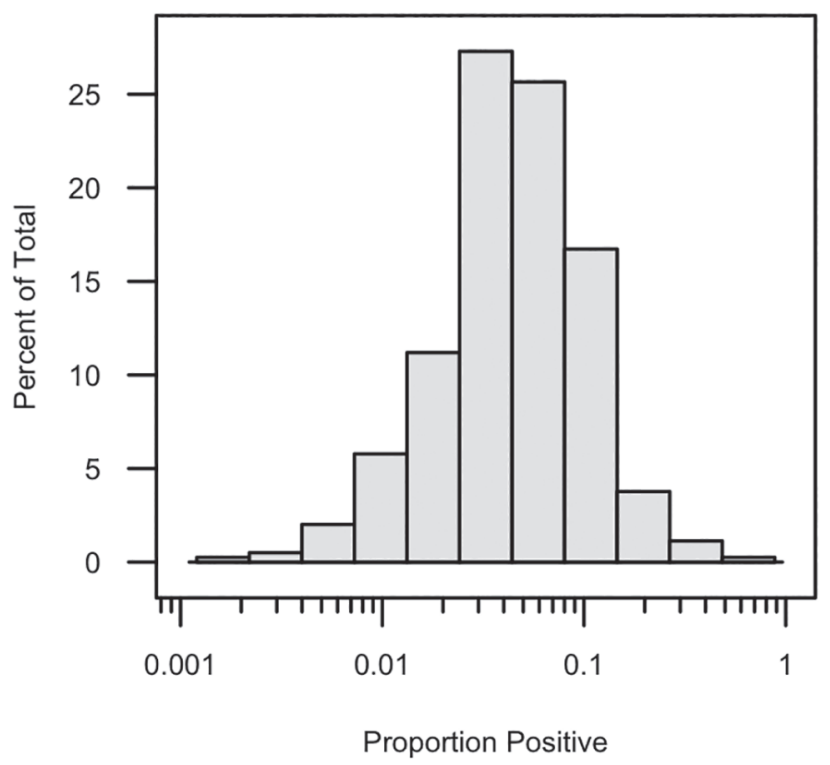

Figure 1. (A) Distribution of number of ELISA tests for antibodies to Mycobacterium avium ssp. paratuberculosis per animal based on the original, unedited data. (B) Distribution of number of test records per herd (Holstein only), with white bars indicating herds included after editing ( $\geq 100$ records per herd). (C) Distribution of daughters per sire (Holstein only, after elimination of sires with unknown identification), with white bars indicating sires included after editing ( $\geq 50$ daughters per sire). (D) Distribution of proportion of positive tests within herd. 
age at test $(P<0.00001)$ and age at test squared $(P<$ 0.00001 ) were found to have a highly significant association with MAP test results. An age at test effect was expected given the progressive nature of Johne's disease, with disease most commonly manifesting at later ages. Herd, age at test, and age at test squared were included in the mixed models used in estimating heritability. Heritability estimates from the linear model were 0.041 $\pm 0.004,0.050 \pm 0.004$, and $0.062 \pm 0.007$ for data from herds with at least 1 positive test, $\geq 2.5 \%$ positive tests, and $\geq 5 \%$ positive tests, respectively. Heritability estimates from the threshold model were $0.157 \pm 0.014$, $0.174 \pm 0.016$, and $0.186 \pm 0.021$ for data from herds with at least 1 positive test, $\geq 2.5 \%$ positive tests, and $\geq 5 \%$ positive tests, respectively. Heritability estimates increased as data were restricted to herds with presumed higher MAP exposure for linear model but not threshold model analyses. Restricting the data to herds with higher proportions of positive test results implies that the herds have an environment in which animals experience a higher exposure to the pathogen, such that their phenotypes provide a truer indication of genotype for susceptibility and correspondingly higher estimate of heritability (i.e., in a high-exposure environment it is less likely that a negative test result reflects absence of exposure versus lesser susceptibility to infection). The higher heritability estimate from TPM versus LM was not unexpected, given that heritability on the observed scale is theoretically the product of heritability on the unobserved liability scale and incidence in the population, such that estimates on the observed scale vary with population incidence, suggesting that the threshold model analysis is the better choice. (Lynch and Walsh, 1998). Heritability estimates for LM and TPM are in good agreement with previous reports of linear model heritability estimates, which ranged from $<0.01$ to 0.183 (Koets et al., 2000; Mortensen et al., 2004; Gonda et al., 2006; Hinger et al., 2008; Attalla et al., 2010; Berry et al., 2010; van Hulzen et al., 2011; Zare et al., 2014; Pritchard et al., 2017), and previous threshold model estimates, which ranged from 0.052 to 0.283 (Gonda et al., 2006; Hinger et al., 2008; Attalla et al., 2010; Berry et al., 2010; Küpper et al., 2012; Shook et al., 2012; Zare et al., 2014). Heritability estimates increased as data were restricted to herds with presumed higher MAP exposure for both linear and threshold model analyses, as previously observed (van Hulzen et al., 2011).

The results reported here indicate that susceptibility to MAP infection is a heritable trait that could be changed by genetic selection. This data set is one of the largest used thus far in estimation of heritability of this trait.

\section{ACKNOWLEDGMENTS}

This project was supported by USDA-NIFA (Washington, DC) grant 2012-02188. We wish to thank AgSource Cooperative Services (Verona, WI) and Dairy Records Management Systems (Raleigh, NC) for providing the phenotypic records used in this study and the National Association of Animal Breeders (Madison, WI) for pedigree data.

\section{REFERENCES}

Attalla, S. A., A. J. Seykora, J. B. Cole, and B. J. Heins. 2010. Genetic parameters of milk ELISA scores for Johne's disease. J. Dairy Sci. 93:1729-1735.

Berry, D. P., M. Good, P. Mullowney, A. R. Cromie, and S. J. More. 2010. Genetic variation in serological response to Mycobacterium avium subspecies paratuberculosis and its association with performance in Irish Holstein-Friesian dairy cows. Livest. Sci. 131:102107.

Gilmour, A. R., B. J. Gogel, B. R. Cullis, S. J. Welham, and R. Thompson. 2015. ASReml User Guide. VSN Int. Ltd., Hemel Hempstead, UK.

Gonda, M. G., Y. M. Chang, G. E. Shook, M. T. Collins, and B. W. Kirkpatrick. 2006. Genetic variation of Mycobacterium avium ssp. paratuberculosis infection in US Holsteins. J. Dairy Sci. 89:18041812

Harris, N. B., and R. G. Barletta. 2001. Mycobacterium avium ssp. paratuberculosis in veterinary medicine. Clin. Microbiol. Rev. 14:489-512.

Hinger, M., H. Brandt, and G. Erhardt. 2008. Heritability estimates for antibody response to Mycobacterium avium subspecies paratuberculosis in German Holstein cattle. J. Dairy Sci. 91:32373244 .

Koets, A. P., G. Adugna, L. L. Janss, H. J. van Weering, C. H. Kalis, G. H. Wentink, V. P. Rutten, and Y. H. Schukken. 2000. Genetic variation of susceptibility to Mycobacterium avium ssp. paratuberculosis infection in dairy cattle. J. Dairy Sci. 83:2702-2708.

Küpper, J., H. Brandt, K. Donat, and G. Erhardt. 2012. Heritability estimates for Mycobacterium avium subspecies paratuberculosis status of German Holstein cows tested by fecal culture. J. Dairy Sci. 95:2734-2739.

Lombard, J. E., I. A. Gardner, S. R. Jafarzadeh, C. P. Fossler, B. Harris, R. T. Capsel, B. A. Wagner, and W. O. Johnson. 2013 Herd-level prevalence of Mycobacterium avium ssp. paratuberculosis infection in United States dairy herds in 2007. Prev. Vet. Med. 108:234-238.

Lynch, M., and B. Walsh. 1998. Genetics and Analysis of Quantitative Traits. Sinauer Associates Inc., Sunderland, MA.

Mortensen, H., S. S. Nielsen, and P. Berg. 2004. Genetic variation and heritability of the antibody response to Mycobacterium avium subspecies paratuberculosis in Danish Holstein cows. J. Dairy Sci. 87:2108-2113.

NAHMS. 2008. Johne's Disease on U.S. Dairies, 1991-2007. USDAAPHIS, Washington, DC.

Naser, S. A., S. R. Sagramsingh, A. S. Naser, and S. Thanigachalam. 2014. Mycobacterium avium subspecies paratuberculosis causes Crohn's disease in some inflammatory bowel disease patients. World J. Gastroenterol. 20:7403-7415.

Norton, S., W. O. Johnson, G. Jones, and C. Heuer. 2010. Evaluation of diagnostic tests for Johne's disease (Mycobacterium avium subspecies paratuberculosis) in New Zealand dairy cows. J. Vet. Diagn. Invest. 22:341-351.

Ott, S. L., S. J. Wells, and B. A. Wagner. 1999. Herd-level economic losses associated with Johne's disease on US dairy operations. Prev. Vet. Med. 40:179-192. 
Pritchard, T., R. Mrode, M. Coffey, K. Bond, and E. Wall. 2017. The genetics of antibody response to paratuberculosis in dairy cattle. J. Dairy Sci. 100:5541-5549.

R Development Core Team. 2010. R: A language and environment for statistical computing. R Foundation for Statistical Computing, Vienna, Austria.

Shin, S. J., D. Cho, and M. T. Collins. 2008. Diagnosis of bovine paratuberculosis by a novel enzyme-linked immunosorbent assay based on early secreted antigens of Mycobacterium avium ssp. paratuberculosis. Clin. Vaccine Immunol. 15:1277-1281.

Shook, G. E., M. Chaffer, X. L. Wu, and E. Ezra. 2012. Genetic parameters for paratuberculosis infection and effect of infection on production traits in Israeli Holsteins. Anim. Genet. 43(Suppl 1):56-64.

van Hulzen, K. J., M. Nielen, A. P. Koets, G. de Jong, J. A. van Arendonk, and H. C. Heuven. 2011. Effect of herd prevalence on heritability estimates of antibody response to Mycobacterium avium subspecies paratuberculosis. J. Dairy Sci. 94:992-997.

Zare, Y., G. E. Shook, M. T. Collins, and B. W. Kirkpatrick. 2014. Short communication: Heritability estimates for susceptibility to Mycobacterium avium subspecies paratuberculosis infection defined by ELISA and fecal culture test results in Jersey cattle. J. Dairy Sci. 97:4562-4567. 